\title{
Notch1 is associated with the multidrug resistance of hypoxic osteosarcoma by regulating MRP1 gene expression
}

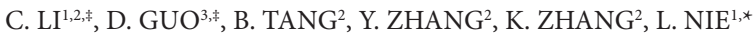

${ }^{1}$ Department of Orthopedics, Qilu Hospital, Shandong University, Jinan, Shandong, 250012, China; ${ }^{2}$ Department of Orthopedics, The Central Hospital of Taian, Taian, Shandong, 271000, China; ${ }^{3}$ Department of Hematology, The Central Hospital of Taian, Taian, Shandong, 271000, China

${ }^{*}$ Correspondence: nielin666@126.com

*Contributed equally to the work.

\section{Received March 21, 2016 / Accepted June 3, 2016}

\begin{abstract}
Hypoxia and Notch signaling pathway are closely related and both participate in cell proliferation and drug resistance of tumors. However, the molecular mechanisms of hypoxia and Notch signaling pathway in cell proliferation and drug resistance of osteosarcoma (OS) remain unclear. In this study, to further evaluate the role of hypoxia and Notch1 on drug resistance of OS, we investigated the influence of inhibiting Notch1 pathway by Notch1 small interference RNA (siRNA) on human MG63 OS cells in hypoxia. Our data showed that hypoxia promoted OS cell proliferation, induced the G0/G1-S-G2/M phase transition, and increased multidrug resistance of human OS cells. Western blot analysis suggested that hypoxia increased the expression of HIF-1 $\alpha$, Notch1, and multidrug resistance protein-1 (MRP1) in human OS cells. Notch1 siRNA inhibits proliferation and increases apoptosis of hypoxic OS cells. Finally, these hypoxic OS cells can be sensitized to multidrug treatment through inhibition of the Notch protein expression by siRNA. Repression of the Notch protein expression resulted in down-regulation of MRP1 protein. These data support the conclusion that Notch signaling is up-regulated in human OS cells under hypoxia and Notch1 may represent a viable target to overcome chemoresistant OS cells in a hypoxic niche by regulating MRP1 gene expression.
\end{abstract}

Key words: hypoxia, HIF-1 $\alpha$, Notch1, multidrug resistance, osteosarcoma

Osteosarcoma (OS) is the most common primary malignant tumors in childhood and adolescence, and is the second leading cause of mortality in this age group. $90 \%$ of patients died of pulmonary metastasis even after radical surgery such as amputation before the advent of multidrug chemotherapy [1]. However, the survival rate has remained almost unchanged for three decades even with the introduction of multiagent chemotherapy. Therefore, new therapeutic options are urgently needed.

Hypoxia is one of the physical microenvironments of solid tumors and is associated with a malignant phenotype, cell invasion, and poor survival [2]. Hypoxia inducible factor-1 (HIF-1), a heterodimeric transcription factor consisting of HIF- $1 \alpha$ and HIF- $1 \beta$ subunits, plays a critical role in cellular response to hypoxic conditions. Under hypoxic conditions, heterodimerized HIF enters the nucleus to bind to hypoxia response elements as the gene promoter for transactivation. Hypoxia may also play a pivotal role in drug resistance in different cancers. The drug resistance induced by HIF1a-mediated P-gp [3-5] or multidrug resistance protein-1 (MRP1) [6-8] expression has been observed in many kinds of tumor cells. However, little is known about the contributing mechanisms of hypoxia-associated therapy resistance in OS. In OS cell lines, hypoxia increases cell migration and promotes chemoresistance independent of HIF-1a [9]. Nevertheless, other studies suggest that HIF-1 is involved in the doxorubicin resistance of OS cells [10]. It is necessary to more clearly elucidate the role of hypoxia in drug resistance of OS.

Notch signaling is one of the most important pathways in tumor microenvironment. The binding of Notch receptor to its ligand results in proteolytic cleavage and the release of the activated intracellular domain of Notch1 (ICN), which translocates to the nucleus and interacts with DNA binding transcriptional repressor recombination signal binding protein-Jk (RBP-Jk). The NICD/RBP-Jk complex transactivates target genes. Notch signaling pathway is pivotal in 
a variety of biological processes, including cell proliferation and apoptosis, as well as stem cell maintenance and differentiation [11]. Notch signaling pathway contributes to the pathogenesis of numerous diseases, and has been described as an oncogene in OS [12]. However, the role of Notch in chemoresistance of OS remains conflicting [13-16]. Further research is needed to evaluate the role of hypoxia and Notch1 on drug resistance of OS.

Hypoxia and Notch signaling pathway are closely related. It has been shown that Notch signaling is regulated by HIF-1 in human leukemia, melanoma, and breast cancer [17-22]. These reports seem to implicate activation of the hypoxia-mediated Notch pathway in tumor cell survival and invasiveness. However, the molecular mechanisms of Notch signaling pathway in the drug resistance of OS in hypoxia remain unclear.

In this study, we first evaluated the effect of hypoxia on human MG-63 OS cell proliferation, cell cycle and chemoresistance, and then we observed the effect of Notch small interference RNA (siRNA) on hypoxic MG-63 OS cell proliferation, cell cycle and chemoresistance. The data we presented show that hypoxia promoted OS cell proliferation, induced the G0/G1-S-G2/M phase transition and increased multidrug resistance of human OS cells, resulted in increased expression of HIF- $1 \alpha$ and Notch1 proteins. In addition, this section also describes our finding of MRP1 protein up-regulation under hypoxic conditions. Followed by further down-regulation of Notch1 using siRNA, the next section contains evidence that hypoxia-induced proliferation and chemoresistance of OS cells are dependent on hypoxia-induced up-regulation of Notch1. Our data indicate that MRP1 may be a downstream target gene of Notch1 and hypoxia induced cytotoxic drug resistance of OS cells via upregulation of MRP1 protein expression.

\section{Materials and methods}

Cell lines and culture. Human osteosarcoma cell line MG-63 was purchased from Type Culture Collection of the Chinese Academy of Sciences (Shanghai, China), and grown in a-MEM (Gibco, Grand Island, NY, USA), containing 10\% FBS (Hyclone, Tauranga, New Zealand) and antibiotics (100 $\mathrm{U} / \mathrm{ml}$ penicillin and $100 \mu \mathrm{g} / \mathrm{ml}$ streptomycin) (Hyclone, Logan, UT,USA). The cell line was maintained at $37^{\circ} \mathrm{C}$ in a humidified 5\% $\mathrm{CO}_{2}$ atmosphere. Hypoxic conditions were achieved by culturing cells in a sealed, anaerobic work station (Concept 400, Ruskin Technologies, Pencoed, Wales, UK), in which the hypoxic environment $\left(1 \% \mathrm{O}_{2}, 94 \% \mathrm{~N}_{2}\right.$ and $\left.5 \% \mathrm{CO}_{2}\right)$, temperature $\left(37^{\circ} \mathrm{C}\right)$, and humidity $(90 \%)$ were kept constant.

Cell viability assays. The MTT assay was used to test cell viability. We seeded growing MG-63 cells into 96-well culture plates in $200 \mu \mathrm{l}$ of media at a density of $1 \times 10^{4}$ cells/well. The cells were placed in the normoxic and hypoxic incubator for $12 \mathrm{~h}, 24 \mathrm{~h}, 48 \mathrm{~h}$ or $72 \mathrm{~h}$. Following the incubation, $20 \mu \mathrm{l}$ MTT (3-(4, 5-dimethylthiazol-2-yl)-2, 5-diphe-nyltetrazolium bromide ( $5 \mathrm{mg} / \mathrm{ml}$ in PBS; Sigma, St. Louis, MO) was added to each well for $4 \mathrm{~h}$. Subsequently, the supernatants were discarded and $150 \mu \mathrm{LMSO}$ was added to each well. After the plates being shaken for $10 \mathrm{~min}$ in dark, absorbance was measured by a microplate reader at a wavelength of $570 \mathrm{~nm}$ (Multiskan GO, Thermo scientific, Waltham, MA).

For the chemotherapeutic sensitivity assay, after being cultured in the normoxic and hypoxic incubator for $24 \mathrm{~h}$, MG63 cells were exposed to different concentration of cisplatin (DDP) (Sigma, St. Louis, MO, USA) $(0-80 \mu \mathrm{M})$, Doxorubicin (DOX) (Sigma-Aldrich, Milan, Italy) $(0-5 \mu \mathrm{M})$, methotrexate (MTX) (Sigma-Aldrich, Milan, Italy) $(0-5 \mu \mathrm{M})$ or Ifosfamide (IFM) (Sigma, St. Louis, MO, USA) $(0-12 \mu \mathrm{g} / \mathrm{ml})$ for an additional $24 \mathrm{~h}$ in the normoxic and hypoxic incubator and the MTT assay was performed as described above.

For the cell viability assay, MG-63 cells were seeded into 96well culture plates in $200 \mu \mathrm{l}$ of media at a density of $1 \times 10^{4} \mathrm{cells} /$ well and then placed in the hypoxic incubator. The cells were transfected with Notch1 siRNA or control siRNA next day according to the manufacturer's recommendations. The cells were placed in the hypoxic incubator for $12 \mathrm{~h}, 24 \mathrm{~h}, 48 \mathrm{~h}$ or 72 h. And the MTT assay was performed as described above.

For the chemotherapeutic sensitivity assay, MG-63 cells were seeded into 96-well culture plates in $200 \mu \mathrm{l}$ of media at a density of $1 \times 10^{4}$ cells/well and then placed in the hypoxic incubator. The cells were transfected with Notch1 siRNA or control siRNA next day according to the manufacturer's recommendations. $24 \mathrm{~h}$ after transfection in the hypoxic incubator, cells were exposed to different concentration of DDP $(0-80 \mu \mathrm{M})$, DOX $(0-5 \mu \mathrm{M})$, MTX $(0-5 \mu \mathrm{M})$ or IFM $(0-12 \mu \mathrm{g} /$ $\mathrm{ml}$ ) for an additional $24 \mathrm{~h}$ in the hypoxic incubator. MTT assay was performed as described above.

Cell cycle analysis. The cell cycle distribution was determined by flow cytometric analysis of propidium iodide (PI) (BD ParMingen, San Diego, CA)-stained nuclei. After siRNA transfection, cells were collected, washed twice with PBS and fixed with $500 \mu \mathrm{l} 75 \%$ cold ethyl alcohol overnight in the dark at $4^{\circ} \mathrm{C}$. Then cells were washed with PBS and incubated with $500 \mu \mathrm{l}$ PI for $15 \mathrm{~min}$ in the dark at room temperature. Following staining, cells were immediately analyzed by flow cytometry. Cells with sub-G1 DNA content were considered apoptotic. We used the "Dean-Jett-Fox" (DJF) model for cell cycle analysis.

SiRNA transfection. For Notch1, sense siRNA is 5'ACGAAGAACAGAAGCACAAAGGCGG-3' and antisense siRNA is 5'-CCGCCUUUGUGCUUCUGUUCUUCGU-3'. For scrambled control, sense and antisense siRNAs are 5'-UUCUCCGAACGUGUCACGUTT-3' and 5'-ACGUGACACGUUCGGAGAATT-3', respectively. Notch1 siRNA (Invitrogen) or the scrambled control siRNA (Invitrogen) was transfected at the final concentration of $100 \mathrm{nM}$ oligonucleotide using the Lipofectamine 2000 reagent (Invitrogen) according to the manufacturer's recommendations. The cells were used for the following experiments.

Western blot analysis. Cells were lysed in lysis buffer [50 mM Tris (pH 7.5), $100 \mathrm{mM} \mathrm{NaCl}, 1 \mathrm{mM}$ EDTA, 0.5\% NP40, 0.5\% Triton X-100, $2.5 \mathrm{mM}$ sodium orthovanadate, 
$10 \mu \mathrm{l} / \mathrm{ml}$ protease inhibitor cocktail, $1 \mathrm{mM}$ phenylmethylsulfonyl fluoride] for $20 \mathrm{~min}$ at $4{ }^{\circ} \mathrm{C}$. The protein concentrations were determined with the BCA Protein Assay reagent (Pierce, Rockford, IL), according to the manufacturer's instructions. Total proteins were fractionated by SDS-PAGE and transferred onto nitrocellulose membrane. Membranes were blocked with blocking buffer [0.1 MTris ( $\mathrm{pH} 7.5$ ), $0.9 \% \mathrm{NaCl}$, and $0.05 \%$ Tween-20 (TBST) containing 5\% nonfat milk powder], then incubated with appropriate primary antibodies against Notch1 (Abcam Ltd., Cambridge, UK), HIF-1 $\alpha$, MDR-1/P-gp, MRP1 (Santa Cruz Biotechnology, Santa Cruz, CA, USA) and $\beta$-actin (Sigma-Aldrich, Milan, Italy), followed by incubation with anti-rabbit or anti-mouse horseradish peroxidase (HRP)conjugated antibodies. The probed proteins were detected using the chemiluminescent reagents (SuperSignal West Pico West Chemiluminescent Substrate, Pierce, Rockford, IL). The bidimensional absorbance of proteins on the films were quantified and analyzed with Molecular Analyst software (Bio-Rad).

Statistical analysis. Statistical analysis was performed using SPSS18.0 software (SPSS Inc., Chicago, IL, USA). Experiments were performed three times and data are expressed as mean \pm standard deviation (SD). The Student's t-test was used to compare the means of the two groups. When more than three means were compared, a one-way analysis of variance followed by multiple comparisons among the means was conducted. Difference was considered statistically significant at $P<0.05$.

\section{Results}

Hypoxia promotes proliferation of osteosarcoma cells. To observe the effects of hypoxia on growth of OS cells, cell

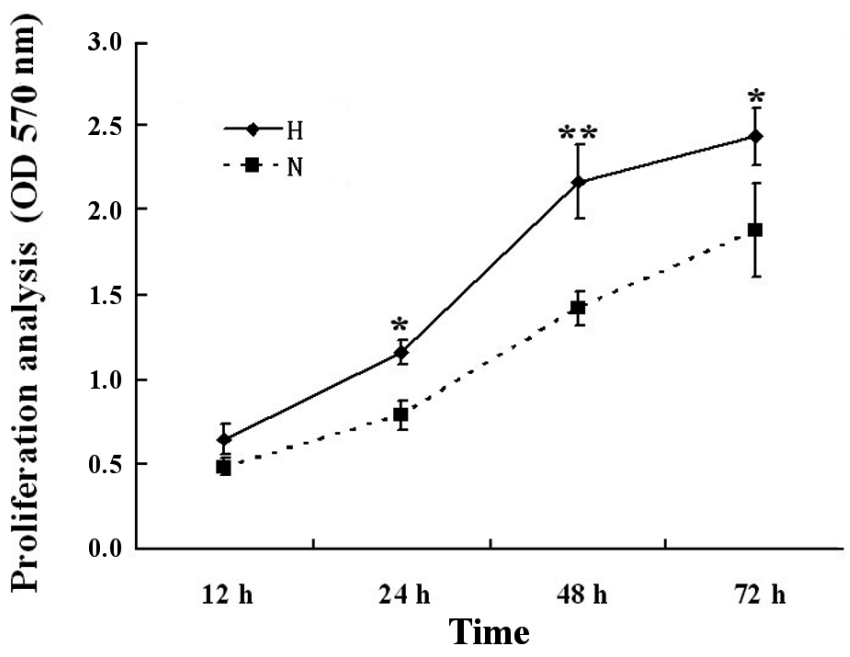

Figure 1. Effect of hypoxia on OS cell proliferation. The proliferation of OS cells under normoxic and hypoxic conditions was measured by MTT assay. ${ }^{\star \star} P<0.01$ versus normoxia group,${ }^{\star} P<0.05$ versus normoxia group. Data are expressed as mean \pm SD of three independent experiments. $H$, hypoxia group; $\mathrm{N}$, normoxia group. proliferation assays were performed at baseline and after $12 \mathrm{~h}$, $24 \mathrm{~h}, 48 \mathrm{~h}$ and $72 \mathrm{~h}$ exposure to hypoxia. The growth curve of MG-63 cells under normoxic and hypoxic conditions was assessed. As shown in Figure 1, 1\% hypoxia for $24 \mathrm{~h}, 48 \mathrm{~h}$ or $72 \mathrm{~h}$ led to consistently accelerated cell growth compared with normoxic conditions $(P<0.05, P<0.01$ or $P<0.05)$. And $1 \%$ hypoxia for $48 \mathrm{~h}$ promoted even a higher level of cell proliferation than normoxic conditions $(P<0.01)$.

Hypoxia induces the G0/G1-S-G2/M phase transition in osteosarcoma cells. As cell proliferation is closely related to cell cycle progression, we analyzed the effects of hypoxia on cell cycle distribution. As shown in Figure 2A-C, 48 h exposure to hypoxia markedly reduced the number of OS cells in the G0/G1 phase of the cell cycle $(P<0.01)$ while concomitantly increasing the number of cells in the $\mathrm{S}(P<0.05)$ and $\mathrm{G} 2 / \mathrm{M}$ phases $(P<0.01)$ compared with those exposed under normoxic conditions.

Hypoxia leads to cytotoxic drug resistance in osteosarcoma cells. To clarify whether hypoxia induces chemoresistance

A

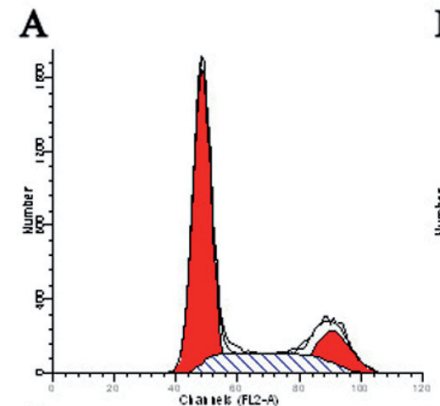

C $\mathbf{N}$

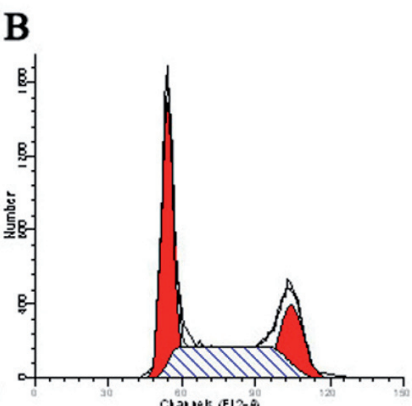

H

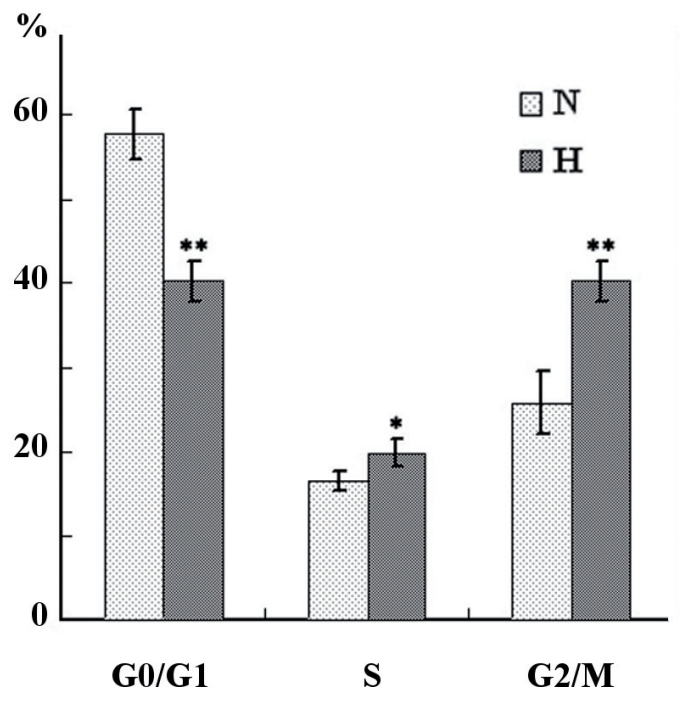

Figure 2. Effect of hypoxia on OS cell cycle distribution. (A and B) OS cells under normoxic and hypoxic conditions for $48 \mathrm{~h}$ were harvested for cell cycle analysis using PI staining. Results shown are representative PI fluorescence histograms of three independent experiments. (C) Cell cycle fractions determined from $A$ and $B$. $H$, hypoxia group; $N$, normoxia group. ${ }^{* *} P<0.01$ versus normoxia group. 
of OS cells, MG-63 cells were cultured under normoxic and hypoxic conditions for $24 \mathrm{~h}$, and then treated with DDP (0-80 $\mu \mathrm{M})$, DOX $(0-5 \mu \mathrm{M})$, MTX $(0-5 \mu \mathrm{M})$ or IFM $(0-12 \mu \mathrm{g} / \mathrm{ml})$ in normoxic or hypoxic conditions for another $24 \mathrm{~h}$ and subjected to chemotherapeutic sensitivity analysis. The dose-response changes for different drug concentrations and inhibition rate indicated an increase in resistance to DDP, DOX, MTX or IFM in hypoxic cells (Figure 3). These results indicate that MG-63 cells under hypoxic conditions were resistance to DDP, DOX, MTX and IFM as compared with normoxic group.

Hypoxia activates the Notch pathway in osteosarcoma cells and increased MRP1 expression. Constitutive expression of HIF- 1 a has been reported in many malignant human cells in vitro under normoxic conditions. We examined the expression level of HIF-1 $\alpha$ in OS cells by western blot. A confirmation of these results was illustrated by showing that HIF-1a protein was constitutively expressed in vitro under normoxic conditions, with a further increase in HIF- 1a protein under hypoxic conditions (Figure 4 ). To address whether hypoxia activates Notch1 in OS cells, we investigated whether the expression of Notch1 protein in OS cells was regulated differently in hypoxia and in normoxia. Our findings indicated that activated Notch1 (Notch1-ICN) was up-regulated in hypoxic conditions (Figure 4). These results confirmed that the Notch1 pathway was more strongly activated in hypoxia than in normoxia. Furthermore, we examined the expressions of MDR1/P-gp and MRP1 protein. Accordingly, the protein level of MRP1 was increased in hypoxia (Figure 4). No significant change of the expression of MDR1/P-gp protein between hypoxic OS cells and normoxic OS cells has been detected. These results indicate that hypoxia induces expression of MRP1, which confers multidrug resistance.

Down-regulation of Notch 1 expression inhibits proliferation of hypoxic osteosarcoma cells. To test whether hypoxia promotes proliferation of OS cells via activation of the
$\mathbf{A}$

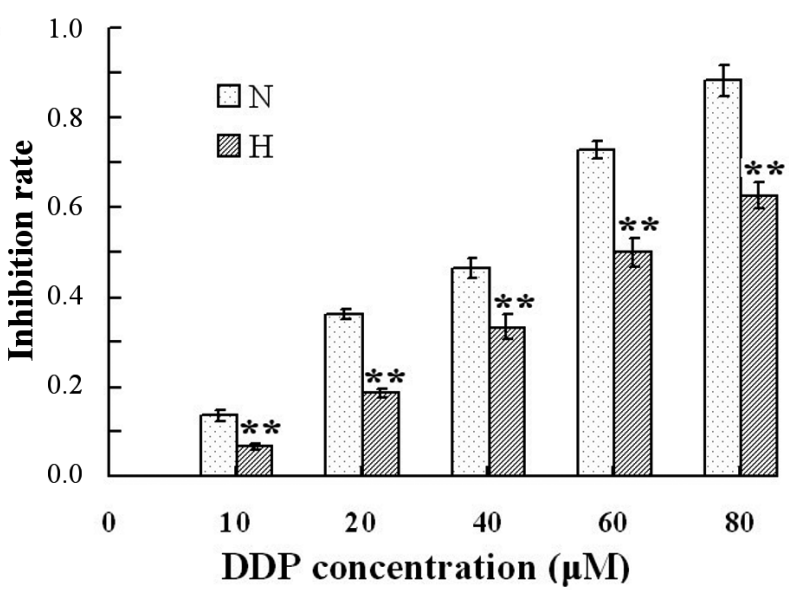

B

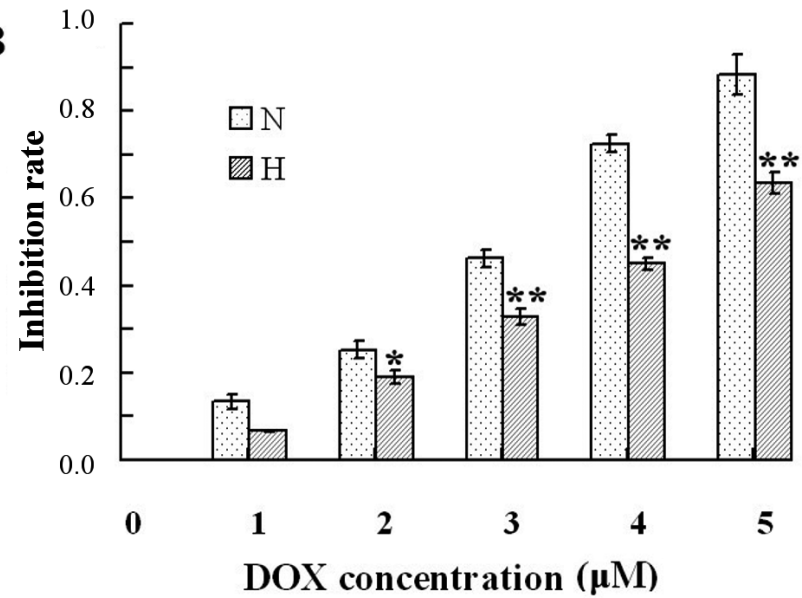

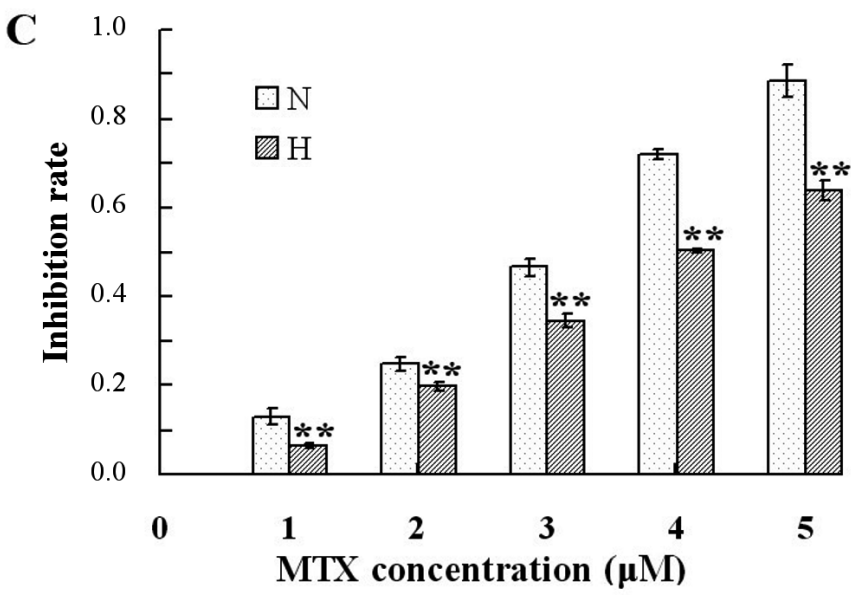

D

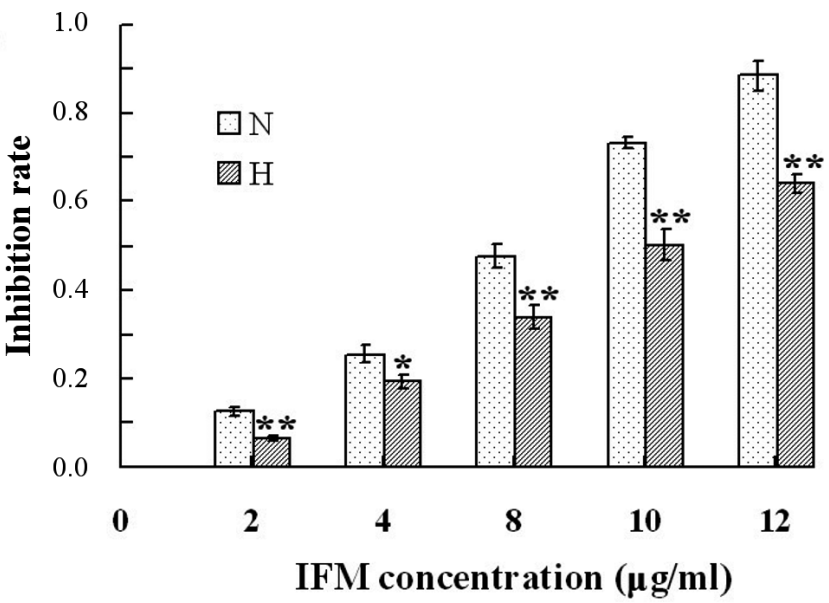

Figure 3. Effect of hypoxia on OS cell sensitivity to DDP, DOX, MTX or IFM. The cells in normoxia group and hypoxia group for $24 \mathrm{~h}$ were treated with different concentration DDP, DOX, MTX or IFM for an additional $24 \mathrm{~h}$ and MTT assay was performed (A, B, C or D). ${ }^{\star *} P<0.01$ versus normoxia group, ${ }^{\star} P<0.05$ versus normoxia group. Data are expressed as mean \pm SD of three independent experiments. $\mathrm{H}$, hypoxia group; $\mathrm{N}$, normoxia group. 
A

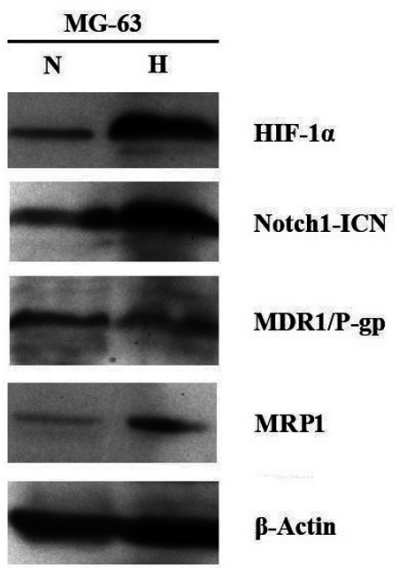

B

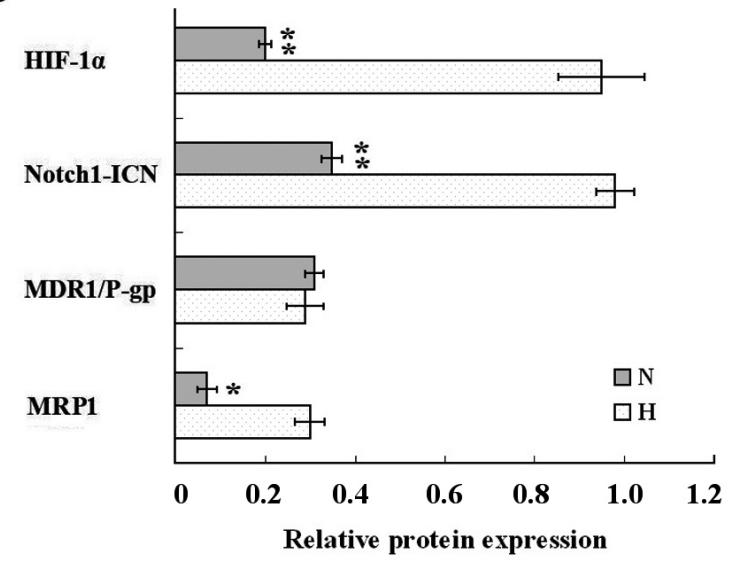

Figure 4. Effect of hypoxia on HIF-1a, Notch1, MDR1/P-gp and MRP1 protein expression. (A) Western blot analysis was done to detect the protein levels. Results are representative of three independent experiments. (B) Densitometric quantification of data presented is shown. The histogram indicates the relative band intensity. Results are expressed as ratio of HIF-1 $\alpha$, Notch 1, MDR1/P-gp and MRP1 protein levels/ $\beta$-actin. Columns, mean of three independent experiments. ${ }^{\star *} P<0.01$ versus normoxia group, ${ }^{\star} P<0.05$ versus normoxia group. Data are expressed as mean \pm SD of three independent experiments. $\mathrm{H}$, hypoxia group; $\mathrm{N}$, normoxia group.

Notch1 signaling pathway, we silenced Notch1 expression in OS using Notch1 siRNA under hypoxic conditions, and then we analyzed the effect of Notch1 siRNA on cell proliferation under hypoxic conditions. $12 \mathrm{~h}, 24 \mathrm{~h}, 48 \mathrm{~h}$ or $72 \mathrm{~h}$ after transfection with Notch1 siRNA or control siRNA under hypoxic conditions, cell viability was detected by MTT assay. Downregulation of Notch 1 expression by siRNA markedly inhibited cell proliferation in MG-63 cells at $48 \mathrm{~h}$ after transfection under hypoxic conditions (Figure 5). These data suggest that

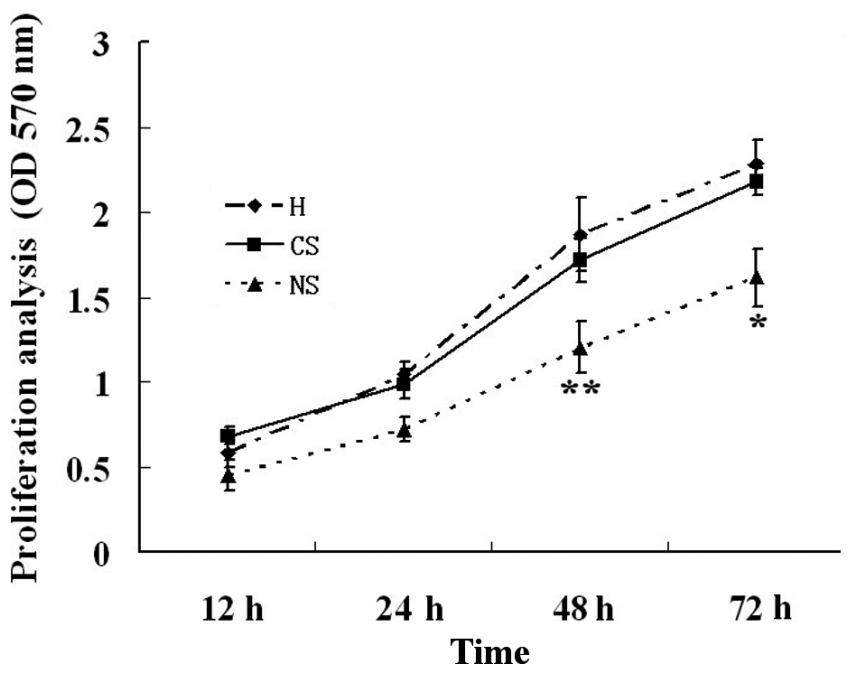

Figure 5. Effect of Notch1 siRNA on hypoxic OS cell proliferation. The proliferation of OS cell was measured by MTT assay. ${ }^{* *} P<0.01$ versus CS group, ${ }^{\star} \boldsymbol{P}<\mathbf{0 . 0 5}$ versus $\mathrm{CS}$ group. Data are expressed as mean \pm SD of three independent experiments. CS, control siRNA-transfected group under hypoxic conditions; NS, Notch 1 siRNA-transfected group under hypoxic conditions; $\mathrm{H}$, untransfected group under hypoxic conditions. hypoxia promotes proliferation of OS cells via the activation of the Notch1 signaling pathway.

Down-regulation of Notch1 expression induces G0/G1 phase cell cycle arrest and increases apoptosis in hypoxic osteosarcoma cells. To observe the effect of down-regulation of Notch1 expression on cell cycle arrest and apoptosis of hypoxic osteosarcoma cells, we knocked down Notch1 expression under hypoxic conditions. Cell cycle analysis showed that silencing Notch1 increased the proportion of cells in the G0/ G1 phase compared with the control group (Figure 6A-C). As shown in Figure 6C, cells with sub-G1 DNA content were considered apoptotic. Notch1 siRNA induced $17.53 \%$ apoptosis of hypoxic OS cells (Figure 6C) compared with control siRNA group under hypoxic conditions.

Down-regulation of Notch1 expression increased drug sensitivity in hypoxic osteosarcoma cells. To further study whether down-regulation of Notch1 expression altered the response of hypoxic OS cells to chemotherapy, we have used siRNA to specifically knock down the expression of Notch1 in MG-63 cells under hypoxic conditions for $24 \mathrm{~h}$, followed by an exposure to cytotoxic agent, and then a further $24 \mathrm{~h}$ exposure under hypoxic conditions. Afterwards, we examined the cell viability. The dose-response inhibition rates for different drug concentrations in Notch siRNA group were increased as compared with control siRNA group (Figure 7). No marked difference was observed between the control siRNA-transfected group and the untransfected group in MG-63 cells under hypoxic conditions (Figure 7). These results strongly support the idea that Notch1 siRNA sensitizes hypoxic OS cells to DDP, DOX, MTX and IFM, and knockdown of Notch1 reverses drug resistance of hypoxic OS.

Down-regulation of Notch1 reduces the expression of MRP protein in hypoxic osteosarcoma cells. To validate that 
A

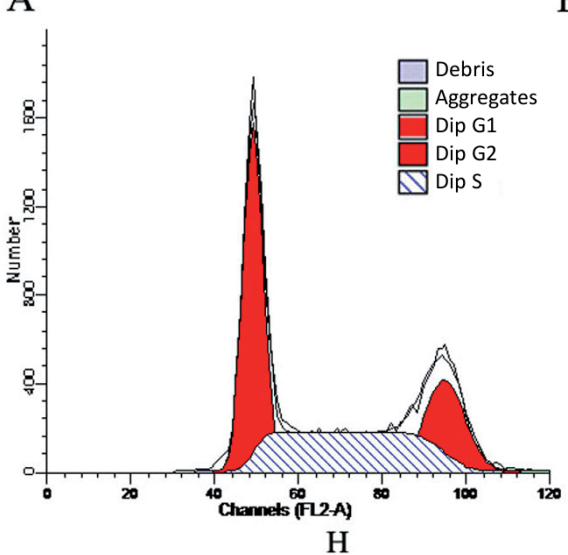

B

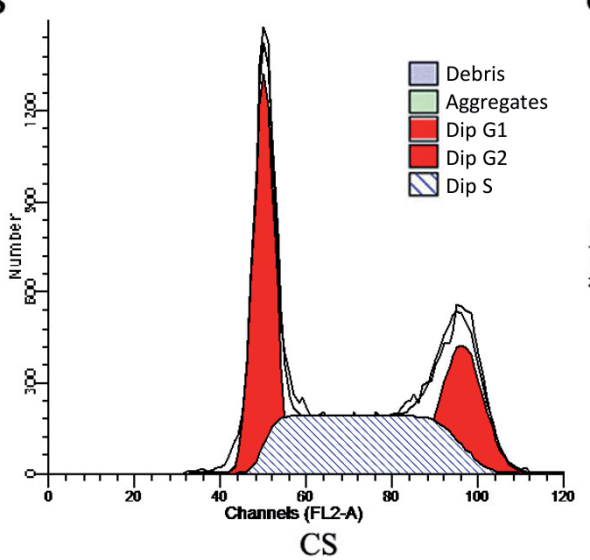

$\mathrm{C}$

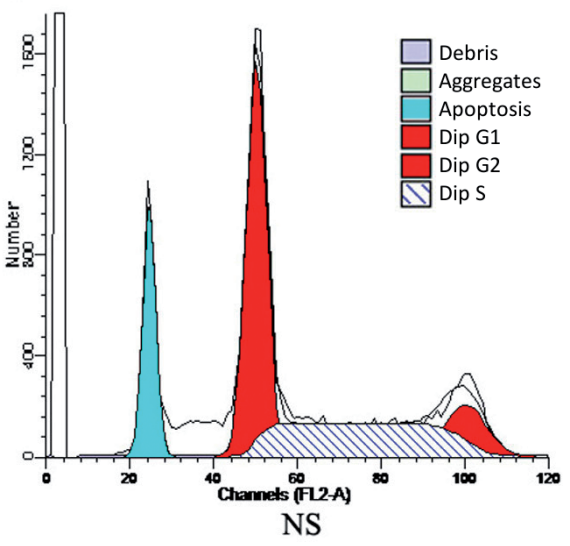

Figure 6. Effect of Notch1 siRNA on hypoxic OS cell cycle distribution. (A, B and C) OS cells under hypoxic conditions were harvested for cell cycle analysis using PI staining after siRNA transfection. Results shown are representative PI fluorescence histograms of three independent experiments. Different colors represent different parameters. CS, control siRNA-transfected group under hypoxic conditions; NS, Notch1 siRNA-transfected group under hypoxic conditions; $\mathrm{H}$, untransfected group under hypoxic conditions.
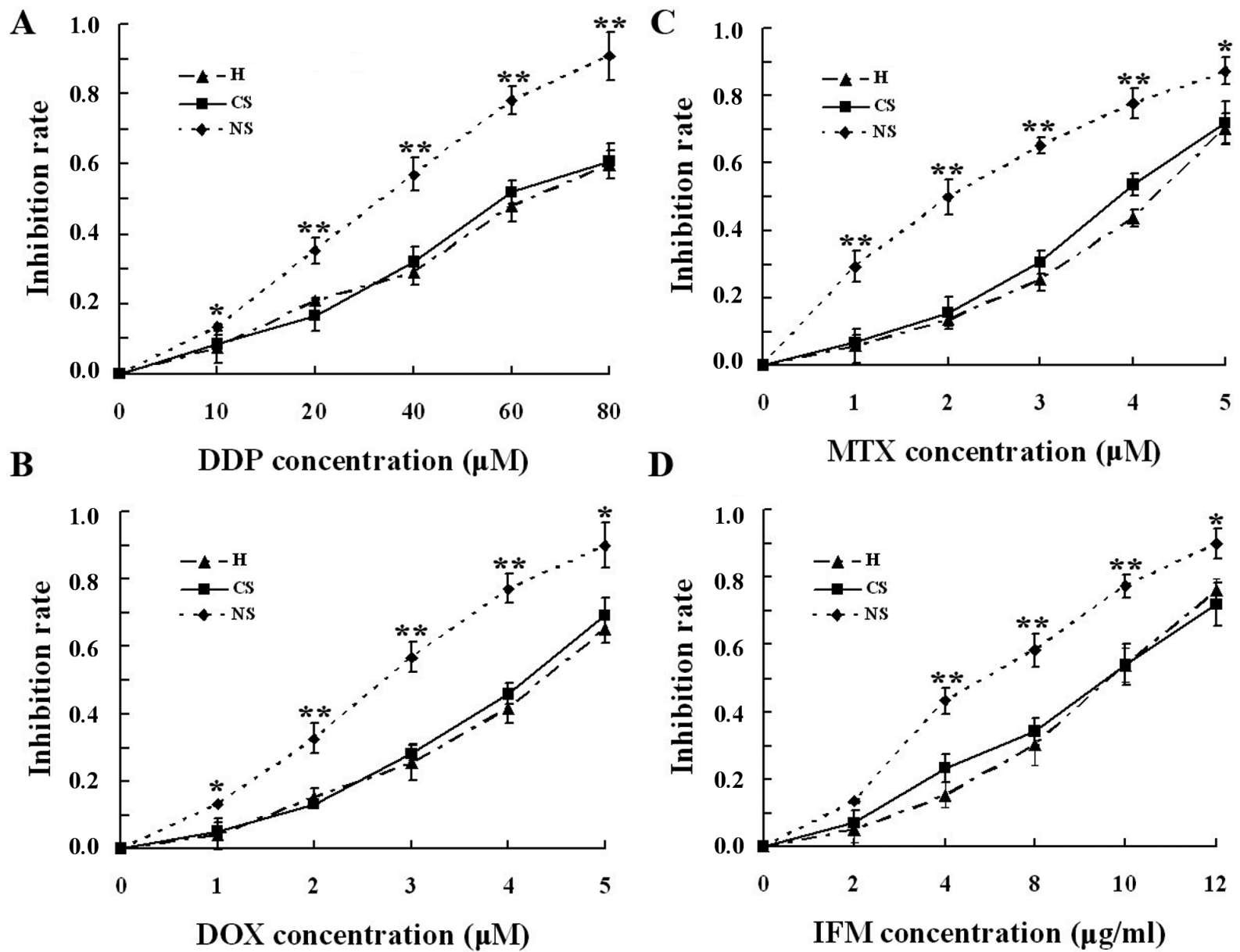

D

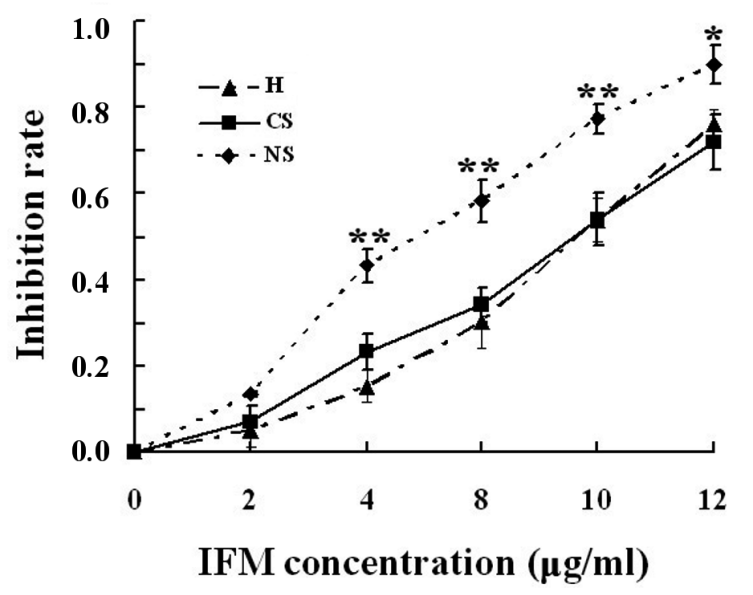

Figure 7. Effect of Notch1 siRNA on hypoxic OS cell sensitivity to DDP, DOX, MTX or IFM. The OS cells transfected with control siRNA (CS) or Notch1 siRNA (NS) were treated with different concentration DDP, DOX, MTX or IFM (A, B, C or D) and MTT assay was performed. ${ }^{* *} P<0.01$ versus CS group, ${ }^{\star} P<0.05$ versus CS group. Data are expressed as mean \pm SD of three independent experiments. CS, control siRNA-transfected group under hypoxic conditions; NS, Notch1 siRNA-transfected group under hypoxic conditions; H, untransfected group under hypoxic conditions. 
A

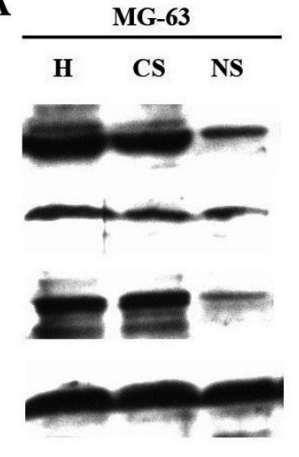

B

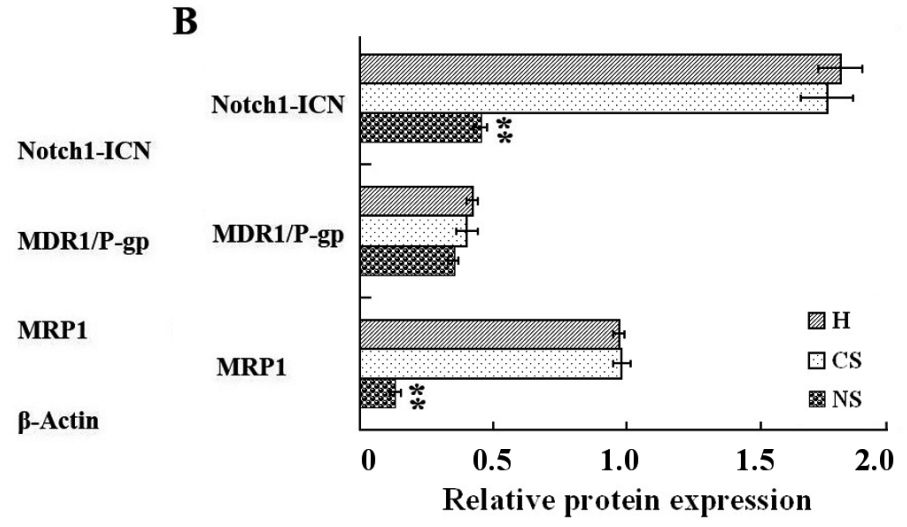

Figure 8. Effect of Notch1 siRNA on Notch1, MDR1/P-gp and MRP1 protein expression. (A) Western blot analysis was done to detect the protein levels. Results are representative of three independent experiments. (B) Densitometric quantification of data presented is shown. The histogram indicates the relative band intensity. Results are expressed as the ratio of HIF-1 $\alpha$, Notch 1, MDR1/P-gp and MRP1 protein levels/ $\beta$-actin. Columns, mean of three independent experiments. Data are expressed as mean \pm SD of three independent experiments. ${ }^{\star \star} P<0.01$ versus $\mathrm{CS}$ group, ${ }^{\star} \boldsymbol{P}<0.05$ versus $\mathrm{CS}$ group. CS, control siRNA-transfected group under hypoxic conditions; NS, Notch1 siRNA-transfected group under hypoxic conditions; H, untransfected group under hypoxic conditions.

the expression of MRP1 is regulated by Notch1, we used siRNA to knockdown the expression of Notch1 in OS cells under hypoxia. Transfection of Notch1 siRNA into MG-63 cells for $48 \mathrm{~h}$ under hypoxic conditions reduced the Notch 1 protein expression (Figure 8). Accordingly, the protein level of MRP1 was reduced after Notch1 siRNA transfection (Figure 8). There was no significant change of the expression of MDR1/P-gp protein between control siRNA-transfected group and Notch1transfected group in MG-63 cells under hypoxic conditions. These data indicate that MRP1 could be a downstream target gene of Notch 1 and hypoxia induces cytotoxic drug resistance of OS cells via upregulation of MRP1 protein expression.

\section{Discussion}

Osteosarcoma is the most common malignant bone tumor, and has a peak incidence in children and young adolescents [23]. Most current treatment protocols of OS including a variety of doxorubicin, cisplatin, high-dose methotrexate, and ifosfamide have greatly improved the prognosis [24]. However, despite the use of many therapeutic methods, the five-year event-free survival (EFS) for metastatic OS is even lower than 20\% [23]. Rapid development of cross-resistance against current drugs has always been a major obstacle in the chemotherapy of OS. Therefore, exploring the mechanism of tumor resistance and finding effective drugs are hot spots for the treatment of OS.

There is increasing evidence that tumor cells often reside in low oxygen conditions. Hypoxic environment promotes accumulation of HIF-1 $\alpha$ and is involved in tumor progression and chemoresistance. It has been reported hypoxia promotes tumor growth in various cell types $[2,25]$. Hypoxia and HIF-1a induce growth factors, which bind to their receptors, inducing a signal cascade leading to cell proliferation and survival [26-
27]. In the current study, we showed that hypoxia promotes proliferation of OS cells. Hypoxia also participates in drug resistance of different kinds of tumor. Knocking down of HIF-1 $\alpha$ by siRNA can significantly reduce the induction of MRP1 by hypoxia in colon cancer [8]. Hypoxia induced MDR in gastric cancer (GC) cells [3]. The research on the role and mechanism of hypoxia in the drug resistance of OS is controversial. Adamski J et al. demonstrated hypoxia-induced cytotoxic drug resistance in OS is independent of HIF-1a [9]. However, other studies suggest that HIF-1 is involved in the doxorubicin resistance of OS cells [10]. It is evident from our research that hypoxia induces multidrug resistance of OS cells. MDR1/P-gp and MRP1 have been reported to be associated with hypoxia-related drug resistance. Our findings also revealed that hypoxia induced an increased expression of MRP1 protein. In addition, an interesting observation is that the expression of MDR1/P-gp protein has no significant change in normoxia and hypoxia condition. Greijer AE et al. [28] reported that hypoxia-induced mitoxantrone resistance in MCF-7 cells was not mediated by MDR1 and MRP1. A recent research showed [29] that chaetominine obviously suppressed MRP1 expression, and enhanced ADR-induced apoptosis and intracellular ADR accumulation in K562/Adr cells. But there was no obvious change of MDR1 mRNA. The effect of hypoxia on the expression of MDR1/P-gp protein needs to be further clarified.

Notch signaling pathway plays an important role in tumor microenvironment [30]. Notch1 signaling has been shown to play an oncogenic role in many tumors. Moreover, Notch1 is associated with resistance to chemotherapy, a major cause of treatment failure and poor outcome [7, 31]. Hypoxia and Notch signaling pathway is closely related to the occurrence and development of tumor [32]. Further, Notch signaling is involved in hypoxia-induced tumor cell migration and 
invasion [22]. Notch1 is required for hypoxia-induced chemoresistance of T-cell acute lymphoblastic leukemia cells [18]. However, the data regarding the role of Notch signaling in OS is conflicting. Inhibition of Notch signaling pathway sensitizes OS cells to chemotherapy [13-14]. But, another study suggests that different doses of doxorubicin have different effects on Notch signal pathway. Low dose of doxorubicin significantly activated Notch signaling pathway, high dose of doxorubicin significantly inhibited Notch pathway [16]. However, Ji P et al. conformed that various doses of doxorubicin activated Notch pathway, and Notch siRNA significantly reduced the effects of doxorubicin on the viability and apoptosis of OS cells [15]. In this study, we assessed the effect of inhibiting Notch1 expression on proliferation, cell cycle and drug sensitivity of OS cells in hypoxia, and in the meantime, we analyzed possible synergism between inhibiting Notch pathway and other anti-cancer agents. Our results show that down-regulation of Notch 1 expression inhibits proliferation and increases apoptosis of hypoxic OS cells. And hypoxic OS cells can be sensitized to DDP, DOX, MTX and IFM by simultaneously down-regulation of Notch 1 . The possible mechanism of restoration of sensitivity to chemotherapy by down-regulation of Notch1 could be associated with repressed the expression of MRP1 protein.

In summary, despite the complexity of signaling pathway alterations under hypoxia, Notch signaling pathway may serve as a viable target for hypoxia-induced chemoresistant OS cell subpopulations. Our work serves as an in vitro model demonstration of how cells under oxygen tensions similar to those in the tumor microenvironment may be susceptible to Notch inhibiting. Our findings should allow us and others to develop new therapeutic approaches involving interference with Notch pathway as a means to reverse chemoresistance of OS cells. Further research needs to be done to examine the biological efficacy of more potent and specific Notch signaling inhibitors on hypoxic OS cells.

Acknowledgments: This study was supported by Grant BS2013SF030 from Bureau of Science and Technology of Shandong Province, and Grant ZR2012HL38 from Shandong Province Natural Science Foundation.

\section{References}

[1] RITTER J, BIELACK SS. Osteosarcoma. Ann Oncol 2010; 21 Suppl 7: vii320-325. http://dx.doi.org/10.1093/annonc/ mdq276

[2] VAUPEL P, MAYER A. Hypoxia-Driven Adenosine Accumulation: A Crucial Microenvironmental Factor Promoting Tumor Progression. Adv Exp Med Biol 2016; 876: 177-183. http://dx.doi.org/10.1007/978-1-4939-3023-4 22

[3] ZHANG H, SUN L, XIAO X, XIE R, LIU C et al. Krüppellike factor 8 contributes to hypoxia-induced MDR in gastric cancer cells. Cancer Sci 2014; 105: 1109-1115. http://dx.doi. org/10.1111/cas. 12483
[4] CHEN J, DING Z, PENG Y, PAN F, LI J ET AL. HIF-1 $\alpha$ inhibition reverses multidrug resistance in colon cancer cells via downregulation of MDR1/P-glycoprotein. PLoS One 2014; 9: e98882. http://dx.doi.org/10.1371/journal. pone.0098882

[5] YANG SY, SONG BQ, DAI SL, YANG KX, JIN-ZHOU et al. Effects of hypoxia-inducible factor-1a silencing on drug resistance of human pancreatic cancer cell line Patu8988/5-Fu. Hepatogastroenterology 2014; 61: 2395-2401.

[6] CHO S, LU M, HE X, EE PL, BHAT U et al. Notch1 regulates the expression of the multidrug resistance gene ABCC1/MRP1 in cultured cancer cells. Proc Natl Acad Sci U S A 2011; 108: 20778-20783. http://dx.doi.org/10.1073/pnas.1019452108

[7] KIM B, STEPHEN SL, HANBY AM, HORGAN K, PERRY SL et al. Chemotherapy induces Notch1-dependent MRP1 upregulation, inhibition of which sensitizes breast cancer cells to chemotherapy. BMC Cancer 2015; 15: 634. http://dx.doi. org/10.1186/s12885-015-1625-y

[8] LV Y, ZHAO S, HAN J, ZHENG L, YANG Z et al. Hypoxiainducible factor-1 $\alpha$ induces multidrug resistance protein in colon cancer. Onco Targets Ther 2015; 8: 1941-1948. http:// dx.doi.org/10.2147/OTT.S82835

[9] ADAMSKI J1, PRICE A, DIVE C, MAKIN G. Hypoxiainduced cytotoxic drug resistance in osteosarcoma is independent of HIF-1Alpha. PLoS One 2013; 8: e65304. http:// dx.doi.org/10.1371/journal.pone.0065304

[10] RONCUZZI L, PANCOTTI F, BALDINI N. Involvement of HIF-1 $\alpha$ activation in the doxorubicin resistance of human osteosarcoma cells. Oncol Rep. 2014, 3: 389-394. http://dx.doi. org/10.3892/or.2014.3181

[11] DONG Y, LONG T, WANG C, MIRANDO AJ, CHEN J et al. NOTCH-Mediated Maintenance and Expansion of Human Bone Marrow Stromal/Stem Cells: A Technology Designed for Orthopedic Regenerative Medicine. Stem Cells Transl Med 2014; 3: 1456-1466. http://dx.doi.org/10.5966/sctm.2014$\underline{0034}$

[12] TAO J, JIANG MM, JIANG L, SALVO JS, ZENG HC et al. Notch activation as a driver of osteogenic sarcoma. Cancer Cell 2014; 26: 390-401. http://dx.doi.org/10.1016/j. ccr.2014.07.023

[13] WANG L, JIN F, QIN A, HAO Y, DONG Y et al. Targeting Notch1 signaling pathway positively affects the sensitivity of osteosarcoma to cisplatin by regulating the expression and/or activity of Caspase family. Mol Cancer 2014; 13: 139. http:// dx.doi.org/10.1186/1476-4598-13-139

[14] MA Y, REN Y, HAN EQ, LI H, CHEN D et al. Inhibition of the Wnt- $\beta$-catenin and Notch signaling pathways sensitizes osteosarcoma cells to chemotherapy. Biochem Biophys Res Commun 2013; 431: 274-279. http://dx.doi.org/10.1016/j. bbrc.2012.12.118

[15] JI P, YU L, GUO WC, MEI HJ, WANG XJ et al. Doxorubicin Inhibits Proliferation of Osteosarcoma Cells Through Upregulation of the Notch Signaling Pathway. Oncol Res 2015; 22: 185-191. http://dx.doi.org/10.3727/096504015X14343704124340

[16] MEI H, YU L, JI P, YANG J, FANG S et al. Doxorubicin activates the Notch signaling pathway in osteosarcoma. Oncol Lett 2015; 9: 2905-2909. http://dx.doi.org/10.3892/ol.2015.3135 
[17] YONEKURA S, ITOH M, OKUHASHI Y, TAKAHASHI Y, ONO A ET AL. Effects of the HIF1 inhibitor, echinomycin, on growth and NOTCH signalling in leukaemia cells. Anticancer Res 2013; 33: 3099-3103.

[18] ZOU J, LI P, LU F, LIU N, DAI J et al. Notch1 is required for hypoxia-induced proliferation, invasion and chemoresistance of T-cell acute lymphoblastic leukemia cells. J Hematol Oncol 2013; 6: 3. http://dx.doi.org/10.1186/17568722-6-3

[19] SAHLGREN C, GUSTAFSSON MV, JIN S, POELLINGER L, LENDAHL U. Notch signaling mediates hypoxia-induced tumor cell migration and invasion. Proc Natl Acad Sci U S A. 2008, 105: 6392-6397. http://dx.doi.org/10.1073/ pnas. 0802047105

[20] VILLA JC, CHIU D, BRANDES AH, ESCORCIA FE, VILLA $\mathrm{CH}$ et al. Nontranscriptional role of Hif- $1 \alpha$ in activation of $\gamma$-secretase and notch signaling in breast cancer. Cell Rep 2014; 8: 1077-1092. http://dx.doi.org/10.1016/j. celrep.2014.07.028

[21] ASNAGHI L, LIN MH, LIM KS, LIM KJ, TRIPATHY A ET AL. Hypoxia promotes uveal melanoma invasion through enhanced Notch and MAPK activation. PLoS One 2014; 9: e105372. http://dx.doi.org/10.1371/journal.pone.0105372

[22] TIAN Q, XUE Y, ZHENG W, SUN R, JI W et al. Overexpression of hypoxia-inducible factor $1 \alpha$ induces migration and invasion through Notch signaling. Int J Oncol 2015; 47: 728-738. http://dx.doi.org/10.3892/ijo.2015.3056

[23] HE JP, HAO Y, WANG XL, YANG XJ, SHAO JF et al. Review of the molecular pathogenesis of osteosarcoma. Asian Pac J Cancer Prev 2014; 15: 5967-5976. http://dx.doi.org/10.7314/ APJCP.2014.15.15.5967

[24] FERRARI S, SMELAND S, MERCURI M, BERTONI F, LONGHI A et al. Neoadjuvant chemotherapy with highdose Ifosfamide, high-dose methotrexate, cisplatin, and doxorubicin for patients with localized osteosarcoma of the extremity: a joint study by the Italian and Scandinavian
Sarcoma Groups. J Clin Oncol 2005; 23: 8845-8852. http:// dx.doi.org/10.1200/JCO.2004.00.5785

[25] HU K, BABAPOOR-FARROKHRAN S, RODRIGUES M, DESHPANDE M, PUCHNER B ET AL. Hypoxia-inducible factor 1 upregulation of both VEGF and ANGPTL4 is required to promote the angiogenic phenotype in uveal melanoma. Oncotarget 2016; 7: 7816-7828.

[26] GARNER EF, BEIERLE EA. Cancer Stem Cells and Their Interaction with the Tumor Microenvironment in Neuroblastoma. Cancers (Basel) 2015; 8.

[27] PARKS SK, CORMERAIS Y, MARCHIQ I, POUYSSEGUR J. Hypoxia optimises tumour growth by controlling nutrient import and acidic metabolite export. Mol Aspects Med 2016; 47-48: 3-14. http://dx.doi.org/10.1016/j.mam.2015.12.001

[28] GREIJER AE, DE JONG MC, SCHEFFER GL, SHVARTS A, VAN DIEST PJ et al. Hypoxia-induced acidification causes mitoxantrone resistance not mediated by drug transporters in human breast cancer cells. Cell Oncol 2005; 27: 43-49.

[29] YAO J, WEI X, LU Y. Chaetominine reduces MRP1-mediated drug resistance via inhibiting PI3K/Akt/Nrf2 signaling pathway in K562/Adr human leukemia cells. Biochem Biophys Res Commun 2016; 473: 867-873. http://dx.doi.org/10.1016/j. bbrc.2016.03.141

[30] LI D, MASIERO M, BANHAM AH, HARRIS AL. The notch ligand JAGGED1 as a target for anti-tumor therapy. Front Oncol 2014; 4: 254. http://dx.doi.org/10.3389/fonc.2014.00254

[31] BHOLA NE, JANSEN VM, KOCH JP, LI H, FORMISANO L et al. Treatment of Triple-Negative Breast Cancer with TORC1/2 Inhibitors Sustains a Drug-Resistant and Notch-Dependent Cancer Stem Cell Population. Cancer Res 2016; 76: 440-452. http://dx.doi.org/10.1158/0008-5472.CAN-15-1640-T

[32] BORGGREFE T, LAUTH M, ZWIJSEN A, HUYLEBROECK $\mathrm{D}$, OSWALD F et al. The Notch intracellular domain integrates signals from Wnt, Hedgehog, TGF $\beta / B M P$ and hypoxia pathways. Biochim Biophys Acta 2016; 1863: 303-313. http:// dx.doi.org/10.1016/j.bbamcr.2015.11.020 